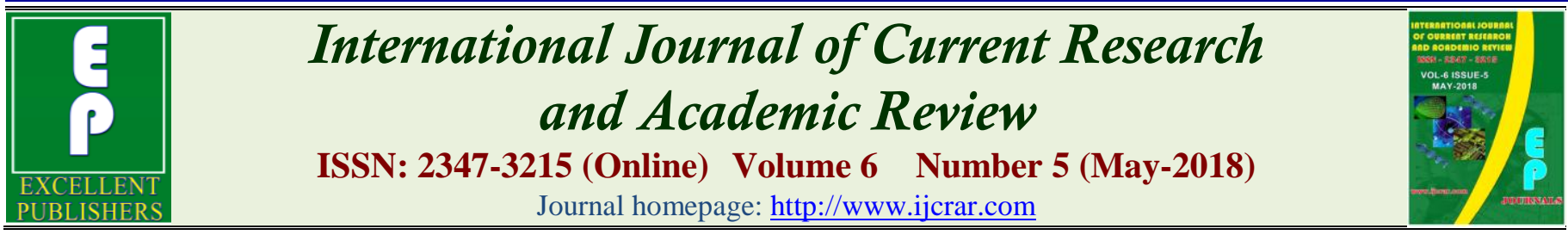

doi: https://doi.org/10.20546/ijcrar.2018.605.010

\title{
Effectiveness of Comprehensive Nursing Intervention on Interpersonal Relationship Skill of Staff Nurses
}

\author{
C.V. Sheeja ${ }^{1 *}$ and K. Reddemma ${ }^{2}$ \\ ${ }^{1}$ MIMS College of Nursing, Vazhayoor, Puthukode PO, Ramanattukara-673633, India \\ ${ }^{2}$ National Consortium for PhD in Nursing, INC, St. John's College of Nursing, Sarjapur Road, Bengaluru- 560034, \\ India \\ *Corresponding author
}

\begin{abstract}
Nurses are able to make good rapport with the clients through their Interpersonal relationship skills. Effective Communication in Nursing is imperative in providing the quality care to the patients. Nurses begin the care to the patients with their therapeutic relationship. The quality of patient care can be improved through the Interpersonal Relationship Skill of Staff Nurses. Interpersonal Relationship Skill can be improved through the continued practice and education. Compare the effectiveness of Comprehensive Nursing Intervention on the enhancement of Interpersonal relationship skills of staff nurses. Evaluative research approach was adopted in the study to evaluate the effectiveness of comprehensive Nursing intervention on the enhancement of Interpersonal relationship skills of staff nurses. Quasi-experimental Non-equivalent control group pre-test - posttest design was selected. Non-Probability method through simple random sampling technique and Interpersonal relationship skills Scale was used to collect data from staff nurses in Bangalore. The Comprehensive Nursing Intervention was effective for making a statistically significant difference in the Interpersonal relationship skills of staff nurses at the 0.001 level (2-tailed) for basic, last day and after one month. The main effect between the period of measurement for Interpersonal relationship skills $\left(\mathrm{F}=554.207^{* *}, \mathrm{P}<0.001\right)$ was found to be significant difference in the mean scores of Interpersonal relationship skills of staff nurses between different measurement period. Interpersonal relationship skills are important in nursing profession because the nurses are providing care to their patients through the Interpersonal relationship skills. Communication between nurses and coworkers, in conjunction with good interpersonal relationships and social interaction are considered indispensable conditions for feeling comfortable with one's work. The wellbeing of nurses is of utmost importance as their wellbeing influences the efficiency of care offered to the patients as well as patient recovery Nurse Administrators can develop effective communicative relationships training programs and strategies for solving communication problems in the organizations.
\end{abstract}

\section{Article Info}

Accepted: 30 April 2017

Available Online: 20 May 2018

\section{Keywords}

IPR= Interpersonal

Relationship Skills

\section{Introduction}

Social skills enable people to maximize effective and productive human interaction. Interpersonal skills will help the individuals to work with others and build rapport with them, but they will also help you to respond to complaints and conflict in a productive manner. Interpersonal communication skills are those which is needed in every day life be it in professional or personal life. Ability to 
communicate correctly has been one of the life's basic social skills ${ }^{1}$.

It is almost impossible for employees to work alone. Everyone needs people around to discuss things and reach to better solutions. The best way is to ignore the person who do not like rather than indulging in conflicts and spoiling relationship. Conflicts turn friends into foes. A smile can actually make a difference.

They are some of the most important skills that is needed to focus on as a large percentage of the life involves interacting with people; friends, colleagues, relations or boss. There is a great difference in the ability to communicate and the ability to communicate effectively.

Interpersonal relationship skills would help to express problems effectively and thus improve the working lives of professionals who work in hospitals every day. Communication between nurses and coworkers, in conjunction with good interpersonal relationships and social interaction are considered indispensable conditions for feeling comfortable with one's work. ${ }^{2}$

Communication is a two-way process and should remain like that. The person should be able to open up to feedback from the other person and give honest feedback whenever it is needed. Most people want to avoid conflict and potentially stressful situations - this is human nature.

Interpersonal relationship skills required for a healthy ambience at the workplace. Improper interpersonal communication leads to negative repercussions for the patient as well as for professionals. Clearly defined roles help to reduce the stress felt by those professionals who take responsibility for the tasks of others, and the nursing staff would no longer feel like they are constantly having to prove their professional worth and credibility. Thus, their professional self-esteem would be enhanced. ${ }^{3}$
People often find it easier to avoid communicating something that they think is going to be controversial or bad, putting off the communication and letting the situation fester. Nursing roles require difficult communication to be handled professionally, with empathy, tact, discretion and clarity.

Use of effective interpersonal communication strategies by nurses in both personal and professional settings, may reduce stress, promote wellness, and therefore, improve overall quality of life. Personal life versus professional role calls us to develop and apply competent skills based on the specific situation, and adopt an appropriate demeanor and response. ${ }^{4}$

Communication is a basic tool in nursing, a crucial element in health care. The quality of the interactions that take place between the nurse and the user/family influences their satisfaction and the security they feel regarding the quality of the care they get from the institution. 5

It also indicates that most barriers to effective communication are associated with the characteristics of healthcare providers and patients. More trainings need to be organized to educate nurses about the professional use of effective communication; awareness of nurses' own characteristics and strategies to understand patient's cues andcharacteristics. ${ }^{6}$

Self-discovery, self-disclosure, and self-validation are contributing critical factors to building and sustaining the interpersonal relationship skills of staff nurses. ${ }^{7}$ Research says productivity increases manifold when individuals work in groups as compared to an individual working alone.

\section{Objectives of the study}

Compare the effectiveness of Comprehensive nursing intervention on the enhancement of Interpersonal relationship skills of staff nurses. 
$\mathbf{H}_{\mathbf{1}}$ : There will be statistically significant difference in mean scores of interpersonal relationship skills of staff nurses after exposure to Comprehensive nursing intervention.

\section{Methodology}

An evaluative approach with a quasi-experimental pretest and post design was used for the study. The sample size consisted of 90 staff nurses from government, corporate and mission hospital, 30 from each setting drawn by using non probability sampling technique by keeping another 90 as control group. The staff nurses meeting the inclusion criteria were selected by simple random sampling using a table of random numbers.

The level of Interpersonal relationship skills was measured by using Interpersonal relationship skills Scale in which Likert rating scale was used. A formal permission was obtained from the Ethical committee and Hospital authorities prior to data collection. Written consent was obtained from individual participants. The data was collected for a period of 90 days from $02-01-15$ to $30-03-15$. The baseline data was collected by administering of Interpersonal relationship skills scale among the experimental groups and control groups.

The Comprehensive Nursing Intervention was administered for the two groups in six sessions with lecture cum discussion. Posttest was carried out after one week to the control group and for experimental group on last day of intervention \& one month follow up using the same tool to assess the knowledge score. The obtained data was analyzed using descriptive and inferential statistics.

\section{Results and Discussion}

The staff nurses reported average mean score for the Interpersonal relationship skills in experimental group $136.83 \pm 18.034$ and control group was 138.11 \pm 11.621 . The Comprehensive Nursing Intervention was effective for making a statistically significant difference in Staff nurses reported of Interpersonal relationship skills mean scores. Both the experimental and control groups were with identical mean score of Interpersonal relationship skills scores before the intervention. The mean scores were increasing as time passes. In the Experimental group Pre- IPR score was $136.83 \pm 18.034$, Post - IPR score was $173.27 \pm 11.959$ \&Follow up -IPRscore was $206.72 \pm 13.583$.

The Comprehensive Nursing Intervention was effective for making a statistically significant difference in the Interpersonal relationship skills of staff nurses at the 0.001 level (2-tailed) for basic, last day and after one month (Figure-1).

The main effect between the period of measurement for Interpersonal relationship skills $(\mathrm{F}=554.207 * *$, $\mathrm{P}<0.001)$ was found to be significant difference in the mean scores of Interpersonal relationship skills of staff nurses between different measurement period. This indicates that there is significant improvement in the Interpersonal relationship skills scores of staff nurses in the experimental group after undergoing comprehensive intervention. (Table1).

Carrier success for Nurses depends on building and maintaining the relationship with other people. Nurses must be able to know when they have to tell the cold, hard truth, and when they need to soften the delivery of information out of human caring. Understanding human nature is important as there are certain basic facts about the nature of human beings.

The present study revealed that staff nurses in both experimental and control group had average level of interpersonal relationship skills before the intervention. There was significant improvement in the level interpersonal relationship skills of staff nurses in the experimental group post intervention.

The findings congruent with a similar study that Siamian Hasan et al (2014) evaluated the interpersonal communication skills among the health care centers staff and indicated that public relation skill, listening, reward and punishment in good scope and other skills were in the average scope. $^{8}$ 
Table.1 Effectiveness of Comprehensive nursing intervention on the of interpersonal relationship skills of staff nurses within subjects effects in experimental group

\begin{tabular}{|c|c|c|c|c|c|c|}
\hline \multirow{2}{*}{ Variable } & Mean & SD & df & $\begin{array}{c}\text { Mean } \\
\text { Square }\end{array}$ & F & Sig. \\
\hline Pre- IPR & 136.83 & 18.034 & & & & \\
\hline Post - IPR & 173.27 & 11.959 & \multirow{2}{*}{1.638} & 134247.248 & $554.207 * *$ & .001 \\
\hline Follow up -IPR & 206.72 & 13.583 & & & & \\
\hline
\end{tabular}

Figure.1 Effectiveness of Comprehensive nursing intervention on the enhancement of interpersonal relationship skills of staff nurses with control group

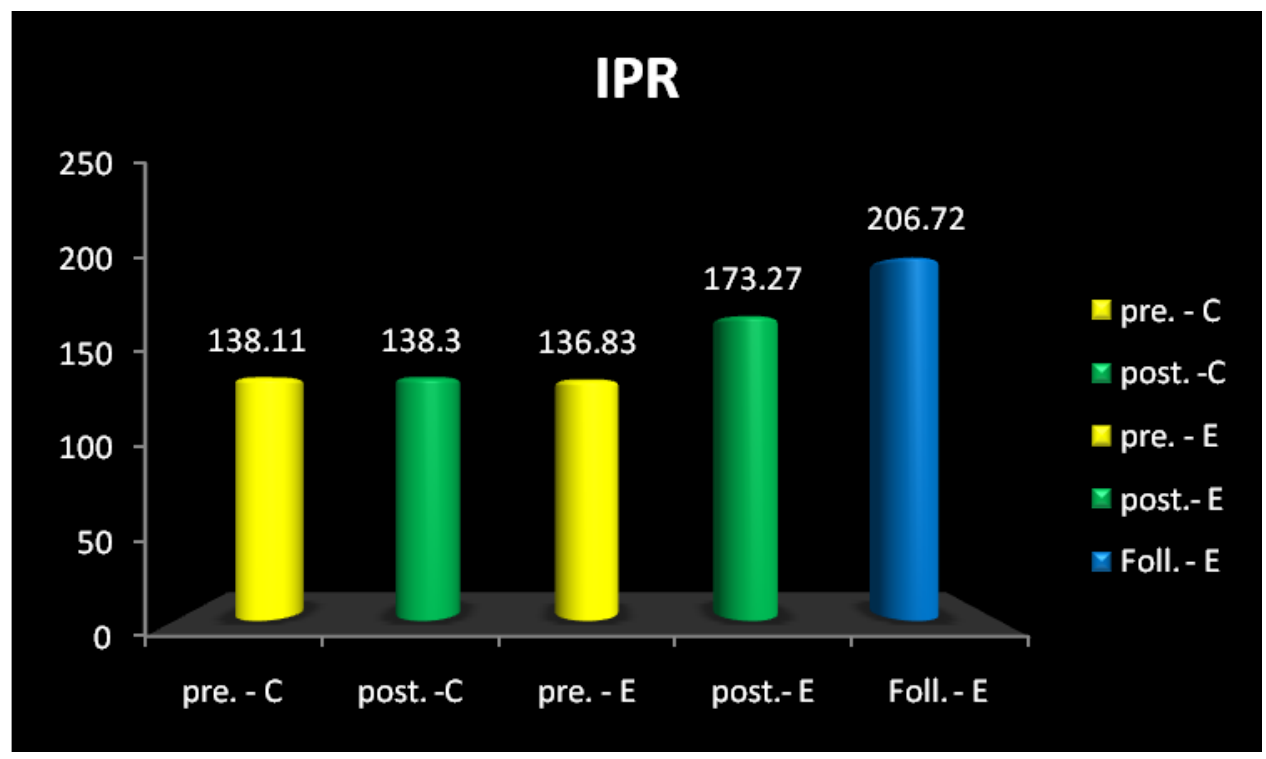

Professional relationships are created through the nurse's application of knowledge and understanding of human behavior, communication of social attitude, motives, and commitment to ethical behavior. Another study conducted by Abdollah et al (2012) reported that interpersonal communication skills training program increased thejob satisfaction among the working nurses. ${ }^{9}$

It is very important to note that the quality of the well- being of the nurses can be improved through good interpersonal relationship skills by learning and practicing, in turn it improves the quality of the nursing care they provide to their patients. Interpersonal relationship skills qualities positively impact the ability to sustain both physical and mental health of staff nurses by increasing the relational skills with everyone.

\section{Recommendation}

Study recommends that Interpersonal relationship skills training or other such techniques may be given to the Staff nurses to build their communication satisfaction, self-concept, self -esteem and other qualities required for improving the soft skills of staff nurses. Interpersonal relationship skills and its training program can be included in graduate nursing program and in nursing curriculum, so that sufficient emphasis can be given to understanding of Soft skills. 


\section{References}

1. Hasan S, Masoumeh B N, Roobabe D N, Fereshteh R N, Hadise A, Azita B, and Mohammad V, Assessment of Interpersonal Communication Skills Among Sari Health Centers' Staff, Mater Sociomed. 2014 Oct; 26(5): 324-328.

doi: $10.5455 / \mathrm{msm} .2014 .26 .324-328$

2. Rickard G, Lenthall S, Dollard M, Opie T, Knight S, Dunn S, et al. Organizational intervention to reduce occupational stress and turnover in hospital nurses in the Northern Territory, Australia. Collegian. 2012 Jul; 19(4):211-21

3. Yolanda R Lapena M , Luis C J , Azucena P M , María L, Interpersonal Relationships among Hospital Nurses and the Use of Communication Skills, Textocontexto enferm. vol.23 no.3 Florianópolis July/Sept. 2014 http://dx.doi.org/10.1590/010407072014002010013

4. Kathleen A. Vertino, DNP, Effective Interpersonal Communication: A Practical Guide to Improve Your Life, OJIN: The Online Journal of Issues in Nursing Vol. 19, No. 3, Manuscript 1., DOI: 10.3912/OJIN.Vol19No03Man01

5. Manuela F, Daniel S, Ana P, Maura S, Monica N, Nina C, Clinical Skills and Communication in Nursing Students,
icH\&Hpsy 2016 : 2nd International Conference on Health and Health Psychology, http://dx.doi.org/10.15405/epsbs.2016.07.02. 5

6. Opeyemi B, Effective Communication in Nursing Practice: A literature review, Bachelor's Thesis Degree Programme in Nursing, 2017

7. Adigwe P, Okoro E (2016) Human Communication and Effective Interpersonal Relationships: An Analysis of Client Counseling and Emotional Stability. Int $\mathrm{J}$ Econ ManagSci 5:336. doi:10.4172/21626359.1000336

8. Siamian H, Nesami M B, Nia R D, Nezhad F $\mathrm{R}$, Akbari H, Balaghafari A, Vahdei $\mathrm{M}$, (2014). Assessment of interpersonal communication skills among Sari Health Centers Staff. Materia Socio Medica. 26(5), 324-28.

9. Abdollah RezaeiDehaghani, Kobra Ahmadi Akhormeh, Tayyebeh Mehrabi. (2012). Assessing the effectiveness of interpersonal communication skills training on job satisfaction among nurses in Al-Zahra Hospital of Isfahan, Iran. Iranian Journal of Nursing and Midwifery Research. 17(4), 290-95.

\section{How to cite this article:}

Sheeja, C.V., and Reddemma, K. 2018. Principal Component Analysis and K-Nearest Neighbor Classifier for Facial Expression Recognition System. Int.J.Curr.Res.Aca.Rev. 6(5), 66-70.

doi: https://doi.org/10.20546/ijcrar.2018.605.010 